\title{
Ă̆ Kafeslerde Sürdürülebilir Balık Yetiştiriciliği için Bir Bilgisayar Yazılımının Kullanımı
}

\author{
Using of the Computer Software for the Sustainable Fish Cage Culture
}

\author{
Beril ÖZDAL ${ }^{1} \quad$ Serap PULATSÜ ${ }^{1}$ \\ ${ }^{I}$ Ankara Üniversitesi Ziraat Fakültesi Su Ürünleri Mühendisliği Bölümü, Ankara
}

\begin{abstract}
Özet: Son yıllarda tüm dünyada ă̆ kafeslerde entansif balı yetiştiriciliğinin artış göstermesi, yetiştiriciliğin çevresel etkileri konusunda da bilinçlenmenin artmasına ve sürdürülebilir yetiștiricilik kavramının önem kazanmasına neden olmuştur. Bu duruma paralel olarak yetiştiriciliğin çevresel etkilerine ilişkin yeni modeller bulunmakta veya var olan modeller gelişen teknoloji ve yetiştiricilik yöntemlerine göre kalibre edilmektedir. Çevre ile dost yetiştiricilik yapabilmek için kısa zamanda güvenilir sonuç verebilecek teknolojik yaklaşımları içeren model uygulamalarına gereksinim duyulmaktadır. Bu çalışmada, ă kafeslerde sürdürülebilir yetiştiricilik için geliştirilen ve -Ă̆ Kafeslerde Yetiştiriciliğe İlişkin Karar Destek Sistemikısaca CADS_TOOL olarak adlandırılan bilgisayar yazılımı sunulmuştur. Bilgisayar yazılımı; alan sınıflandırması, alan seçimi, a ă kafeslerde taşıma yoğunluğu $\left(\mathrm{kg} / \mathrm{m}^{3}\right)$ - alıcı ortamın taşıma kapasitesinin tahmini ile işletmelerin ekonomik açıdan değerlendirilmeleri şeklindeki dört modülü kapsamaktadır. Bu dört modülü oluşturan kriterlerin, ăg kafeslerde balık yetiştiriciliği yapan işletmeler için saha ve laboratuar çalışmalarından elde edilecek veriler doğrultusunda belirlenmesi gereklidir. Çalışma kapsamında kullanımı önerilen yazılımın, hızl ve kolay uygulanabilir olması nedeniyle, Türkiye'de farklı sucul ekosistemlerde dă̆llım gösteren ă̆ kafes işletmelerinin yönetimi ve yetiştiriciliğin çevresel etkilerinin izlenmesi konusunda anahtar rol oynayacă̆ düşünülmektedir.
\end{abstract}

Anahtar kelimeler: Ağ kafeslerde balık yetiştiriciliği, Taşıma kapasitesi, Bilgisayar yazılımı.

\begin{abstract}
In the recent years, a world-wide substantial increase in the intensive aquaculture caused an increase of awareness in the environmental impacts of fish farming and sustainable farming to become important. So, for the effect of the cage aquaculture, new models are developing or existent models are calibrating with the new technological and culture techniques. There's a necessity of a model-eco-friendly aquaculture- which can give reliable results in a short time and has technological information about cage aquaculture for the sustainable farming. In this study, application of a decision support system for the sustainable cage aquaculture developing programme-shortly CADS_TOOL-is presented. The programme has four modules; site classification, site selection, holding density $\left(\mathrm{kg} \mathrm{m}^{-3}\right)$ - carrying capacity and economical apprasial. The program's criteria must be determined for the cage farms in line with the results of the field and laboratory analysis. The programme proposed in this study, is fast and easily applicable, and thought to play a key role in the subject of the management of different cage farms in distinct aquatic ecological areas and monitoring of the environmental impacts of fish farming in Turkey.

Keywords: Cage culture, Carrying capacity, Computer software.
\end{abstract}

\section{Giriş}

Ülkemizde son yıllarda yetiştiriciliğin geliştirilmesi amacı ile alıcı ortamlarda ağ kafeslerde yapılan su ürünleri yetiştiriciliği, kaliteli proteinin ana kaynağı olmasına karşın, bazı kaygı ve sorunları da gündeme getirmiştir. Bunların başında su ürünleri yetiştiriciliğinin alıcı ortamlarda oluşturabileceği çevresel baskı gelmektedir (Yavuzcan vd., 2010). Alıcı ortamın morfometrik ve hidrolojik parametreleri gözetilmeksizin yapılan yoğun balık yetiştiriciliğinde, yem ve dışkı atıkları sedimentte, partikül halde bulunan veya çözünen besin elementleri ise su kolonu üzerinde birtakım olumsuz etkiler yaratmaktadır. 
Balık kafeslerinden alıcı ortama giren karbon ve azot içeren katı organik materyalin bir kısmı (yaklaşık \% 15'i) askıda katı madde olarak su kolonunda kalabilmekte, bir kısmı ise kafes dışındaki ortamda yaşayan canlılar tarafindan tüketilebilmektedir. Önemli bir kısmı sedimentte birikerek bentik sistemin organik zenginleşmesine, bentik makrofauna ve sediment kimyasında değişimlere neden olabilmektedir (Ackefors ve Enell, 1990). Su kalitesindeki başlıca değişimler azot ve fosfor derişimlerindeki değişimler ile karakterize edilirken, sediment kalitesindeki değişimler toplam azot, toplam fosfor, toplam karbon, organik madde ve redoks potansiyelindeki değişimleri kapsamaktadır (Demir vd., 2001; Alpaslan ve Pulatsü, 2008). Ağ kafeslerde balık yetiştiriciliğinin sürdürülebilirliğine ilişkin tehditleri en aza indirebilmek için, yetiştiriciliği destekleyen sistemler geliştirilmeye çalışılmaktadır.

$\mathrm{Bu}$ çalışmada, izleme programları ile çevresel kalite standartlarının bir arada bulunduğu MOM (Modelling-Ongrowing Fish Farms-Monitoring) sistemi ve bu sisteme dayanarak oluşturulan bir bilgisayar yazılımının kullanılabilirliği değerlendirilmiştir. Bilgisayar yazılımının hızlı ve kolay uygulanabilir olması, Türkiye'de farklı ekosistemlerde dağılım gösteren ağ kafes işletmelerinin yönetimi ve yetiştiriciliğin çevresel etkilerinin izlenmesinde, emek ve zaman açısından katkı sağlayabilecektir.

\section{2. İzleme Programı ve Çevresel Kalite Standartları}

Yetiştiricilik yapılan birçok bölgede izlenen olumsuz etki, sedimentte yem ve dışkı atıklarının birikmesiyle ortaya çıkmaktadır. Bentik alanın anoksik hale gelmesi, faunanın fakirleşmesi, metanhidrojen sülfit gibi gazların oluşması ve patojen organizmaların artması istenmez.

Ervik vd. (1997)'ne göre izleme programı; işletmelerin çevresel etkileri bağlamında hata düzeyini minimize etme ve daha ayrıntılı bilgi edinme prensibine dayanır. Böylece az kullanılan bölge ile yüksek düzeyde kullanılan bir bölgenin karşılaştırılması mümkün olmaktadır. Kullanımın derecesi; balık işletmelerinin çevreye yapmış olduğu etkinin, işletmenin bulunduğu bölgenin taşıma kapasitesi ile karşılaştırılması olarak tanımlanır. Kullanım derecesindeki artışı belirtmek için üç izleme seviyesinden yararlanılmaktadır. Bu seviyeler çevresel etkinin derecesine bağlıdır. Birinci ve ikinci izleme-araştırma tipleri için sıklık dereceleri Çizelge 1'de verilmiştir. Üçüncü izleme-araştırma tipi için ise kesin bir sıklık derecesi bulunmamaktadır (Hansen vd., 2001).

Çizelge 1. Bir bölgenin kullanım derecesi ile izleme seviyeleri arasındaki ilişki.*

\begin{tabular}{|c|c|c|c|}
\hline \multirow[b]{2}{*}{ Kullanım derecesi } & \multirow[b]{2}{*}{ İzleme seviyesi } & \multicolumn{2}{|c|}{ Araştırma tipi } \\
\hline & & 1. araştırma & 2. araştırma \\
\hline 1 & 1 & Her üç ayda bir & Her iki yılda bir \\
\hline 2 & 2 & Her iki ayda bir & Her y1l \\
\hline 3 & 3 & Her ay & Her altı ayda bir \\
\hline
\end{tabular}

Birinci izleme-araştırma tipinde, ağ kafeslerin tabanından işletme kaynaklı organik çıktıların belirlenebilmesi için örnekler sediment kepçeleriyle toplanmakta, belirli aralıklarla tekrarlanan ölçümler, işletme tabanındaki sedimentin kalitesi ve aşırı yemleme hakkında bilgi verilebilmektedir. İşletmelerin iç kontrol yapabilmeleri için planlanan bu araştırma tipi çevresel kalite standartları için kullanılmamaktadır.

İzleme programına ilişkin ikinci araştırma tipinin kullanımı daha uygun, kolay ve ucuzdur. Bu araştırma tipi, bentik etki alanı hakkında uzmanlara ve işletme sahibine nitelikli ve nicelikli bilgiler vermekte, işletmelerin sedimenti açısından lokal etki alanının belirlenmesinde kullanılmaktadır.

Üçüncü izleme-araştırma tipinde ise organik yönden zenginleşmiş fauna çalışmalarına dayanarak bentik makrofauna toplulukları incelenmektedir. Bu araştırma tipi uzun vadeli çevresel değişimleri, sedimentte lokal etki alanı ve orta düzeyde etki alanı arasında bir kesit meydana getirerek 
ve bölgesel etki alanındaki birikim bölgelerini belirterek göstermektedir. Bu araştırma tipi ikinci araştırma tipinden daha az kullanılmaktadır (Ervik vd., 1997).

\subsection{MOM yöntemi kavramı}

MOM yöntemi kavramı; kapasiteleri farklı olan işletmelerden kaynaklanan atıklardan, balık işletmelerinin bulunduğu alanların etkilenmesinin az ya da çok olabileceği temeline dayanmaktadır. Başka bir deyişle MOM yöntemi, çevresel etki değerlendirmesine, etkinin izlenmesine ve çevresel kalite standartlarının bir sistemde toplanarak, bu çevresel etki derecesinin hesaplanmasını esas alır. MOM yöntemi genel olarak, çeşitli ülkelerde çevresel problemlerin çözümü için kullanılabilecek bir model olarak görülmektedir.

Çizelge 2'de teorik olarak MOM yönteminin ana unsurları gösterilmektedir. Çevresel değerlendirme tercihen bir modele göre yapılmalı ve balık işletmesinin ana çevresel etkisinin ne olduğu tahmin edilmelidir. Bu yapılan tahmin daha sonra izleme programıyla kabul ya da red edilir. Çevresel kalite standartları, kabul edilebilir maksimum etki değerleri ve olması gereken etki değerleri arasındaki farkın ayırt edilebilmesinde kullanılmaktadır. Bölgenin kullanım derecesi, o bölgeye yapılan etkiyle taşıma kapasitesi arasındaki karşılaştırmanın bir ifadesidir. Eğer üretimin etkisi taşıma kapasitesine yakınsa, o bölgenin kullanım derecesi yüksektir. Eğer kullanım düşükse çevreye olan etki de daha az ya da taşıma kapasitesine yakın demektir. Kullanım derecesi iki ya da üç kategoriye ayrılabilmekte ve bu kategoriler izleme programının seviyesine bağlı olmaktadır. Yüksek derecede kullanım, yüksek seviyede izleme, daha sık görülen yaygın ve ayrıntılı sonuçlar verecektir. Başka bir deyişle, izleme programı ve çevresel kalite standartları faal olan bir işletmenin o bölgenin taşıma kapasitesini aşmayacağının garantisidir (Ervik vd., 1997).

Çizelge 2. MOM yönteminin içeriği hakkında genel bilgi.*

\begin{tabular}{|c|l|}
\hline Model & İşletme kaynaklı atıkların çevreye olan etkilerinin matematiksel bir ifadesidir. \\
\hline İzleme programı & $\begin{array}{l}\text { İşletmenin çevreye olan etkilerinin belirlenmesi için yapılan rutin ölçümlerdir. Farklı inceleme } \\
\text { tiplerini içermektedir. }\end{array}$ \\
\hline $\begin{array}{c}\text { Çevresel kalite } \\
\text { standartları }\end{array}$ & $\begin{array}{l}\text { İzleme programı ve modelin içerdiği değişkenlere ilişkin sınır değerleri içermektedir. Bu sınır } \\
\text { değerler aşıldığı takdirde taşıma kapasitesi de aşılmıs demektir. }\end{array}$ \\
\hline Kullanım derecesi & $\begin{array}{l}\text { Bölgenin taşıma kapasitesi ile işletmenin çevreye olan etkisi arasındaki ilişkidir. Taşıma } \\
\text { kapasitesi aşıldığı takdirde bölge aşırı kullanıma maruz kalıyor demektir. }\end{array}$ \\
\hline İzleme seviyesi & $\begin{array}{l}\text { İzleme programının performansı hakkında bilgi verir. Her derece kullanım için farklı bir } \\
\text { izleme seviyesi bulunur. }\end{array}$ \\
\hline
\end{tabular}

* (Ervik vd., 1997).

\subsubsection{MOM yöntemi izleme programı}

İzleme programı yetiştiricilik yapılan alanlardaki karışıklığı ve zararlı etkileri minimuma indirmek için geliştirilmiştir. Balık işletmelerinin bulunduğu geniş bir bölgenin izleme altına alınabilmesi için, izleme stratejilerinin değerlendirilmeleri ve ortaya çıkan metodların standardize edilmesi gerekmektedir. Yetiştiricilik yapan bir işletmenin çevreye olan etkisi, genellikle düzenli olarak yapılan kimyasal veya biyolojik analizlerin değerlendirilip ekolojik değişikliklerin izlenebildiği alanlarda mümkündür. Hangi çevresel etkinin üzerinde daha çok durulması gerektiğine karar vermek için dört kriter bulunmaktadır:

1) Etki çevresel açıdan ve işletmedeki balıklar üzerinde tespit edilebilir olmalıdır,

2) Etki izlenebilir yani ölçülebilir-belirlenebilir bir işaret vermeli ve bu işaret geçmiş seviyelere göre ayırt edilebilir olmalıdır,

3) Çevresel kalite standartlarını tespit etmek için yeterli bilgi mevcut olmalıdır,

4) İzleme masrafsız olmalı ve rutin metotlarca kullanıma elverişli olmalıdır. 
MOM yöntemi kapsamındaki izleme programı özellikle bentik etki üzerinde durmaktadır. Bentik etki, kafes işletmesinin bulunduğu suyun derinliğine ve balıkların durumuna bağlıdır. Birçok durumda bulgular, sedimentin durumuna göre değişiklik gösterse de sedimentteki organik zenginleşme ile ilgili veriler çevresel kalite standartları ile ilgili değerin bulunmasında yeterli olmaktadır. Sedimentteki organik madde miktarının artışı aerobik, anaerobik ve sülfat redüksiyon süreçlerini baskılayabilmektedir. Sedimentte meydana gelen organik zenginleşme, metan bakterileri tarafindan gaz kabarcıklarının meydana gelmesine, $\mathrm{pH}$ 'nın düşmesine, metan gazı ve 1800 ppm'e ulaşan hidrojen sülfit oluşumuna neden olmaktadır. Su kolonu parametreleri de izleme programına dahil edilmelidir. A $\breve{g}$ kafeslerdeki özellikle oksijen miktarı işletmelerde gelişmekte olan balıklar için önemli bir kriter olduğundan diğer kriterlerden ayrı izlenmesi önerilmektedir (Hansen vd., 2001).

Balık işletmelerinden kaynaklanan maddelerin farklı yayılma, su kolonunu, deniz tabanını ve işletme etrafındaki bölgeyi etkileme potansiyeli bulunmaktadır. Bir balık işletmesi etrafındaki etki alanının belirlenmesi, işletmenin büyüklügüne, bölgenin doğal koşullarına ve işletmenin yönetimine bağlıdır. MOM yönteminde üç farklı düzeyde etki bölgesi bulunmaktadır. Bu bölgelerin (lokal, orta ve bölgesel) ayrımında işletmelerin atıkları dikkate alınmaktadır. Her bölge etkilenme alanına göre karakterize edilmekte ve bu etki şekline göre izlenmektedir (Çizelge 3).

Çizelge 3. MOM yönteminde bölgelendirme.*

\begin{tabular}{|c|c|c|c|}
\hline & Lokal etki alanı & Orta etki alanı & Bölgesel etki alanı \\
\hline Tanım & $\begin{array}{l}\text { İşletmeye yakın alanlarda } \\
\text { dibe çöken madde miktarı } \\
\text { daha fazla olmaktadır. Akış } \\
\text { h1zı ve su derinliği diğer etkili } \\
\text { unsurlardır. }\end{array}$ & $\begin{array}{l}\text { Lokal etki alanının dışında, } \\
\text { çözünmemiş askıda katı } \\
\text { maddenin } \\
\text { çöktüğü alandır. }\end{array}$ & $\begin{array}{l}\text { Orta etki alanının dışında, } \\
\text { işletme } \\
\text { çözünmemişaklı } \\
\text { taşındığı bölgedir. }\end{array}$ \\
\hline $\begin{array}{l}\text { Etkinin } \\
\text { kaynağ }\end{array}$ & $\begin{array}{l}\text { Çevresel etkinin ana kaynağ } 1 \\
\text { işletme aktiviteleridir. }\end{array}$ & 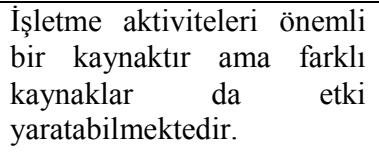 & $\begin{array}{ll}\text { İşletme aktiviteleri } & \text { etkinin } \\
\text { kaynaklarından } & \text { sadece } \\
\text { biridir. } & \end{array}$ \\
\hline $\begin{array}{l}\text { Potansiyel } \\
\text { etki }\end{array}$ & $\begin{array}{l}\text { Sedimentte kimyasal - } \\
\text { biyolojik değişimler, oksijen } \\
\text { miktarında azalma ve besin } \\
\text { elementlerinde artış görülür. }\end{array}$ & $\begin{array}{l}\text { Sedimentte kimyasal, } \\
\text { biyolojik değişimler ve } \\
\text { hipernutrifikasyon görülür. }\end{array}$ & $\begin{array}{lr}\text { Suyun dip bölgelerinde } \\
\text { birincil üretimde ve oksijen } \\
\text { tüketiminde } \\
\text { sözkonusudur. }\end{array}$ \\
\hline İzleme & $\begin{array}{l}\text { Öncelikli olarak birinci ve } \\
\text { ikinci araştırma tipi önerilir. }\end{array}$ & $\begin{array}{l}\text { Üçüncü } \quad \text { araştırma } \\
\text { önerilir. }\end{array}$ & $\begin{array}{l}\text { Üçüncü araştırma tipi ve } \\
\text { genel kıyısal şeridi izleme } \\
\text { önerilir. }\end{array}$ \\
\hline
\end{tabular}

* (Hansen vd., 2001)

\subsubsection{MOM yönteminde taşıma kapasitesi tahmin modeli}

MOM yönteminde taşıma kapasitesi; balık işletmesi sedimentindeki makrofaunaya zarar gelmeksizin maksimum balık üretimi olarak tarif edilmektedir. Sediment canlı organizma barındıramaz duruma geldiğinde taşıma kapasitesi aşılmış demektir. MOM yöntemi öncelikli olarak yetiştiriciliğe başlayacak işletmeler için taşıma kapasitesi tahmini yapılmasını sağlamaktadır. Ayrıca faal olan işletmelerin de çevreye verdikleri etkinin değerlendirilmesinde kullanılmaktadır. Modelin optimum tahmin yapabilmesi için spesifik çevre koşullarının bilinmesi gerekmektedir. Bu değerler su derinliği, akış hızı, oksijen konsantrasyonu, amonyum miktarı ve yıllık sıcaklık değişimleri gibi özelliklerdir. Taşıma kapasitesi, kafeslerin boyutuna ve yönüne, maksimum balık üretim miktarına, yemin içeriğine ve yemleme miktarına da bağlıdır (Stigebrandt vd., 2004).

\section{3. Ăg Kafeslerde Sürdürülebilir Yetiştiricilik için Geliştirilen Bilgisayar Yazılımı (CADS_TOOL)}

Halide vd. (2008) tarafından, Asya'da balık yetiştiriciliğinin yaklaşık \% 95'inin ağ kafeslerde yapıldığı ve üretimin bölgede düzenli olarak artış göstererek 2004 yılında yetiştiriciliğin 1,7 milyon 
tona ulaştığ1 bildirilmiştir. Hızla gelişen bu sektörün, doğal çevreye zarar vermeden sürdürülebilirliğini sağlayacak programların bulunup geliştirilmesinin de bir zorunluluk olduğu vurgulanmıştır. Sürdürülebilir yetiştiriciliği destekleyen birçok sistem mevcuttur, bunlardan bazısı çevresel etkiler dikkate alınarak geliştirilmiş olup, yetiştiricilik yapılacak bölgenin seçilip ruhsatlandırılmasında kullanılırken, bazıları da tesislerin dizaynında, kuluçkahane yönetiminde, yeni üretim tahminlerinin yapılmasında ve su ürünleri yetiştiriciliği yönetiminin kolaylaştırılmasında kullanılmaktadır.

MOM yöntemi; alan sınıflandırmada, birkaç alandan en iyisini seçmede, sürdürülebilir yetiştiriciliğin seçilen alanda yapılabilmesi için taşıma kapasitesinin tahmininde ve ekonomik değerlendirmelerin yapılmasında kullanılan bir programdır ve tüm bu unsurlar CADS_TOOL (Cage Aquaculture Decision Support Tool) denilen bir bilgisayar programında bir araya getirilmiştir (Şekil 1) CADS_TOOL sürdürülebilir yetiştiricilik için Güney Doğu Asya yetiştiricilik endüstrisi tarafından bulunmuş ve Avustralya Deniz Bilimleri Enstitüsü sayfasından ücretsiz olarak indirilip kullanılabilmektedir. Alan kalite sınıflandırması, alan seçimi, taşıma yoğunluğu-taşıma kapasitesi ve ekonomik değerlendirme hesaplamaları olmak üzere dört modül, bu yazılım içine yerleştirilmiş ve Java adlı programı içeren her bilgisayarda kullanılabilir hale getirilmiştir. Taşıma yoğunluğu modülünde dört farklı tahmin modeli bulunmaktadır. Bilgisayar yazılımının en avantajlı yanı her modülün kolayca yapılabiliyor olmasıdır (Halide vd., 2009).

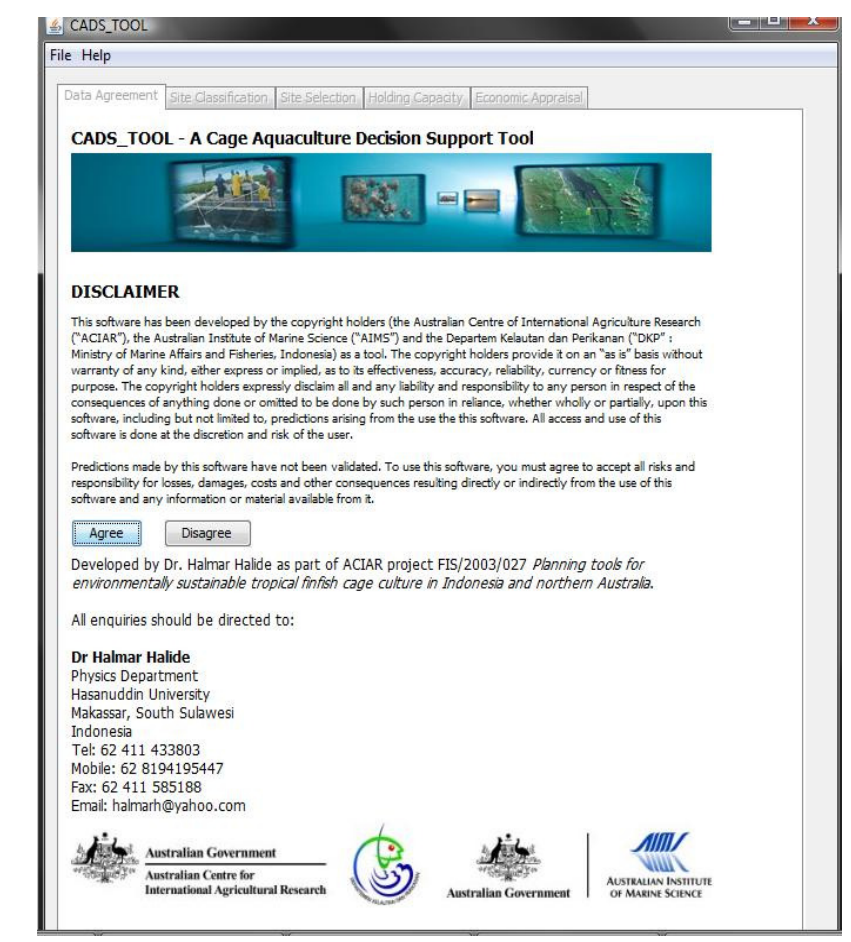

Şekil 1. CADS_TOOL giriş sayfası (Halide vd., 2009).

\subsection{Alan siniflandirmasi}

Bu modülde yetiştiricilik yapılacak alan su kalitesi, substrat kalitesi, hidrometeoroloji ve sosyoekonomik faktörlere göre iyi, orta ve kötü olmak üzere üç grup altında sınıflandırılmaktadır. Her sınıfın kriter ve alt kriterleri bulunmaktadır (Çizelge 4).

$\mathrm{Su}$ kalitesi; oksijen konsantrasyonu, amonyum konsantrasyonu ve Secchi derinliği, substrat (sediment) kalitesi; tekstür, redoks potansiyeli ve organik madde oranı, hidrometeoroloji; akış hızı, önemli dalga yüksekliği ve su derinliği, sosyo-ekonomik faktörler ise pazar, altyapı ve yasal 
düzenlemelere göre belirlenmektedir (Şekil 2). Kullanıcı ölçülen değerleri programa girdiği zaman sonuçlar otomatik olarak hesaplanmaktadır.

Çizelge 4. Bir bölgenin yetiştiricilik açısından uygun alan sınıflandırmasını yapmak için kullanılan kriter ve alt kriterler.*

\begin{tabular}{|c|c|c|c|c|c|}
\hline \multirow[b]{2}{*}{ No. } & \multirow[b]{2}{*}{ Kriter ve alt kriter } & \multicolumn{4}{|c|}{ Sinıflandırma } \\
\hline & & İyi & Orta & Kötü & RI \\
\hline 1 & Su kalitesi & & & & 30 \\
\hline 1.1 & $\mathrm{NH}_{4}(\mathrm{mg} / \mathrm{L})$ & $<0.5$ & $0.5-1.0$ & $>1.0$ & 40 \\
\hline 1.2 & Çözünmüş oksijen (mg/L) & $4-7$ & & $<4$ & 35 \\
\hline 1.3 & Secchi derinliği $(\mathrm{m})$ & $>4$ & $2-4$ & $<2$ & 25 \\
\hline 2 & Substrat kalitesi & & & & 20 \\
\hline 2.1 & Tekstür & Kum & & Çamur & 30 \\
\hline 2.2 & Redoks potansiyeli (mV) & $>(-200)$ & & $<(-200)$ & 45 \\
\hline 2.3 & Organik madde (\%) & $3-8$ & & $>8$ & 25 \\
\hline 3 & Hidrometeoroloji & & & & 40 \\
\hline 3.1 & Akış hızı $(\mathrm{cm} / \mathrm{sn})$ & $5-20$ & & $<1 ;>50$ & 50 \\
\hline 3.2 & Önemli dalga yüksekliği (m) & $<0.5$ & $0.5-1.0$ & $>1.0$ & 10 \\
\hline 3.3 & Su derinliği $(\mathrm{m})$ & $10-30$ & & $<10 ;>30$ & 40 \\
\hline 4 & Sosyo-ekonomik & & & & 10 \\
\hline 4.1 & Pazar & Yakın & & Uzak & 45 \\
\hline 4.2 & Altyap1 & Uygun & & Değil & 35 \\
\hline 4.3 & Yasal düzenlemeler & Uygun & & Değil & 20 \\
\hline
\end{tabular}

* (Halide vd., 2009)

Çizelge 4'deki kriterlerden, çözünmüş oksijen konsantrasyonu (mg/L) 0-10, amonyum konsantrasyonu (mg/L) 0-180 arası değer almaktadır. Tekstür değerleri ise; 1 (çamur), 2 (çamurlu kum), 3 (kum) şeklindedir. Redoks potansiyeli -250 ile +250 arası, akış hızı 0-300 cm/sn arası değerler almaktadır. Su derinliği değerleri ise 0-100 m arasında değişmektedir (Halide vd., 2009).

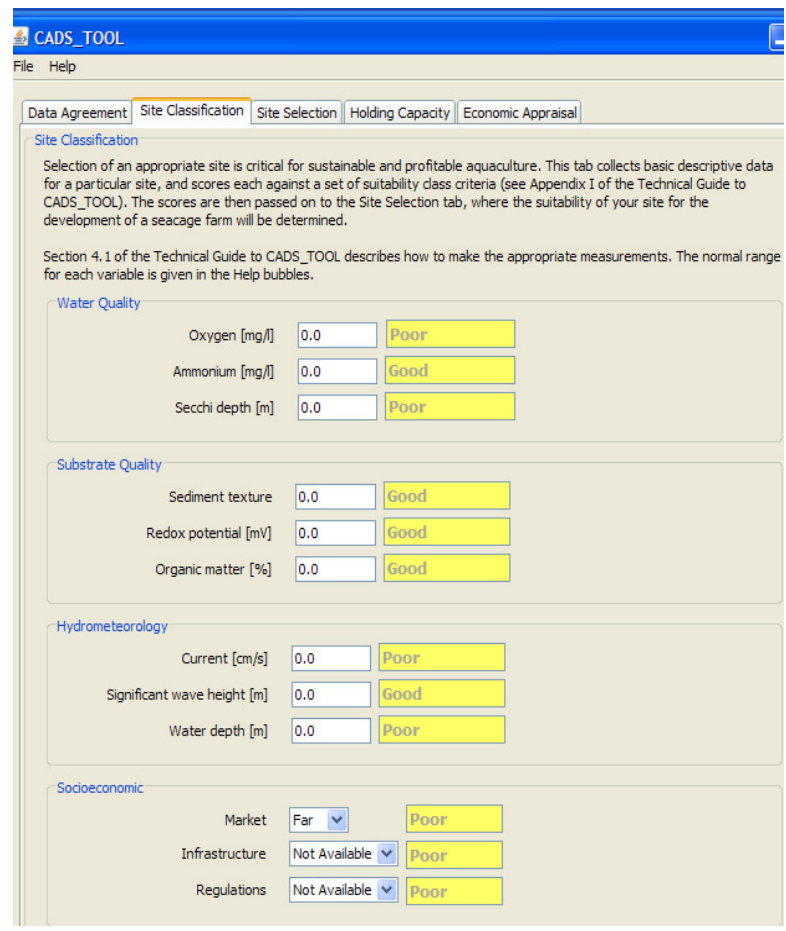

Şekil 2. Alan sınıflandırması modülü (Halide vd., 2009). 


\subsection{Alan seçimi}

$\mathrm{Bu}$ modülün amacı her bir potansiyel bölge için uygun değeri belirlemektir. Bu değerler kötü, orta ve iyi şeklindedir. Değerler analitik hiyerarşi prosesi (AHP) olarak adlandırılan çoklu kriter karar analiz sistemi uygulaması adındaki bir yöntem ile elde edilmektedir. $\mathrm{Bu}$ yöntem; çevresel çalışmalarda, mühendislik dizaynlarında, yönetim projelerinde, balıkçılık yönetiminde, su ürünleri yetiştiriciliği yapılacak bölgenin seçiminde, köprü yapımında ve kontamine olmuş sediment çalışmalarında kullanılmaktadır.

Bilgisayar yazılımında, alan sınıflandırma modülünden elde edilen değerler otomatik olarak alan seçme modülüne geçmektedir. Alan seçme ise dört farklı kriter aracılığıyla hesaplanmaktadır. Her kriterin üç alt kriteri bulunmaktadır (Şekil 3). Kullanıcı tarafından sadece göreceli önem (RI-Relative importance) değerleri tahminsel olarak \% 1-100 şeklinde girilmektedir (Çizelge 4). Kriter ve alt kriterlere verilen göreceli önem değerleri toplamda 100 olmalıdır. Alan seçimi değerler girildikten sonra otomatik olarak program tarafindan belirlenmektedir (Halide vd., 2009).

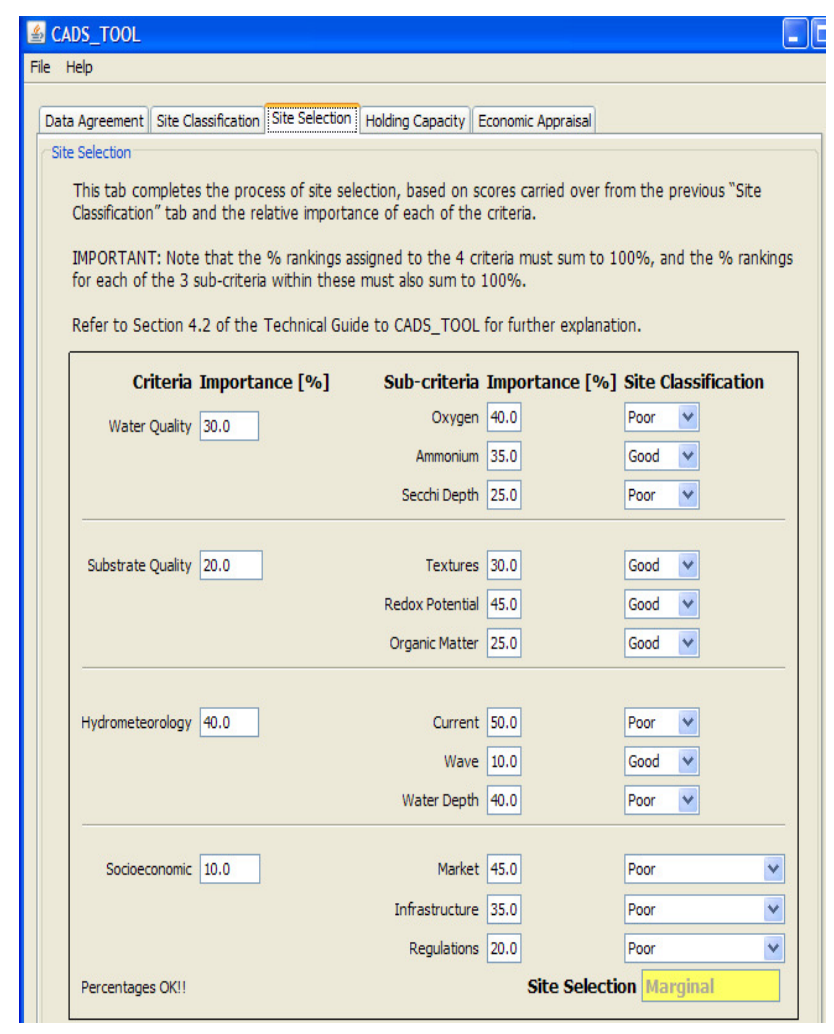

Şekil 3. Alan seçimi modülü (Halide vd., 2009).

\subsection{Taşıma yoğunluğu ve taşıma kapasitesi}

$\mathrm{Bu}$ modülün ası amacı ağ kafeste izin verilebilir maksimum balık biyokütlesinin hesaplanmasıdır. Çevresel şartlar, kullanılan yem rasyonu ve kafes yerleşimi, kafeslerde aylık olarak maksimum ne kadar balık yetiştirilebileceğini etkileyen unsurlardır.

CADS_TOOL; taşıma yoğunluğunun hesaplanmasında, denizlerde ağ kafeslerde balık yetiştiriciliği için Stigebrandt vd. (2004) tarafindan geliştirilen basitleştirilmiş MOM modelini, taşıma kapasitesinin tahmininde ise Tookwinas vd. (2004) ve Hanafi vd. (2006) tarafindan basitleştirilmiş MOM yöntemi baz alınarak geliştirilen modeller ile göl/baraj gölleri için Pulatsü (2003) tarafından kullanılan fosfor bütçe modeli olmak üzere dört farklı modülü içermektedir (Halide vd., 2009). 


\subsubsection{Basitleștirilmiş MOM modeli}

MOM yöntemi, Stigbrandt vd. tarafından aylık maksimum balık üretiminin (taşıma yoğunluğu) tahmin edilmesi için geliştirilmiştir. Maksimum balık üretim tahmini yapılırken de yem, kafes düzeni ve var olan çevresel koşullar göz önünde bulundurulmaktadır. Modelin orjinalinde yirmisekiz adet girdi bulunmaktadır. Modelin basitleştirilmesi için yüz adet simulasyonla çalışılma yapılmış ve gerekli olan girdi değerleri seçilerek girdi sayısı azaltılmıştır (Halide vd., 2009, Şekil 4). Bu modül için gerekli olan girdiler; yüzey akış hızı, kafesteki kritik oksijen konsantrasyonu, kafes tabanındaki kritik oksijen değeri, kafesteki amonyum konsantrasyonu, kafesteki kritik amonyum konsantrasyonu, yemin kuru madde düzeyi, yem değerlendirme oranı, işletmenin uzunluğu ve kafes sıra sayısıdır. Elde edilen değerler programa girildikten sonra taşıma yoğunluğu otomatik olarak hesaplanmaktadır.

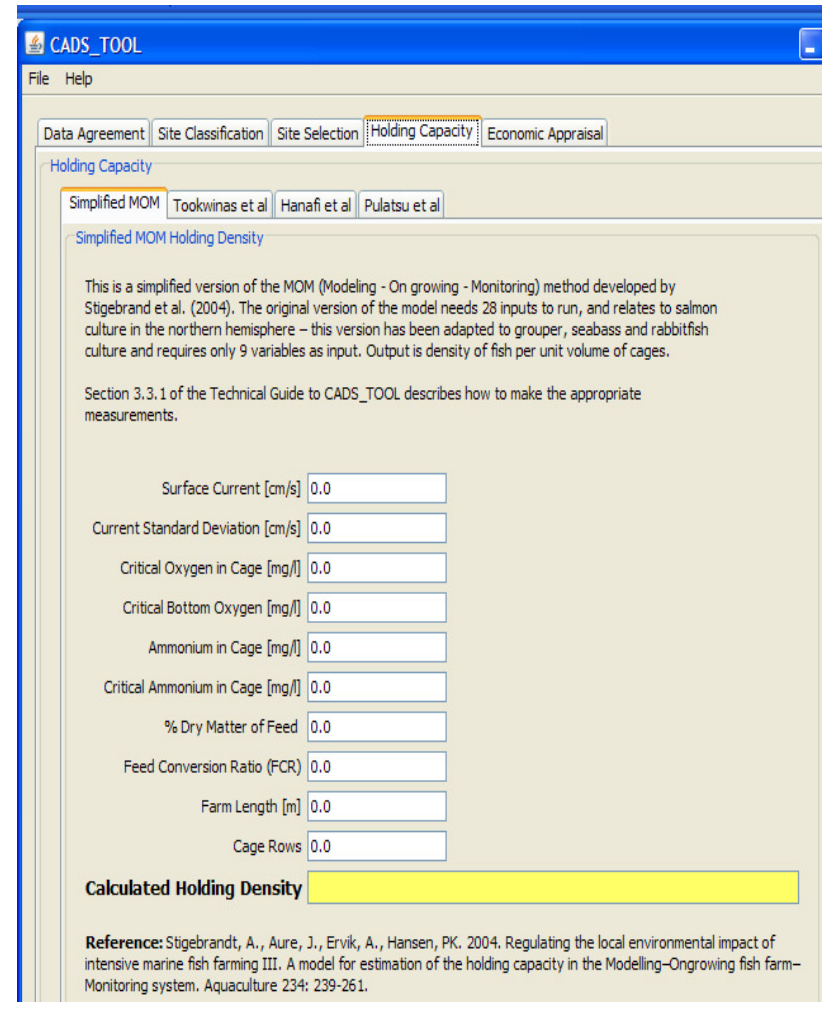

Şekil 4. Taşıma yoğunluğunun tahminine ilişkin basitleştirilmiş MOM modeli (Halide vd., 2009).

\subsubsection{Tookwinas vd. modeli}

Tookwinas vd. modeli, Thailand'da denizde levrek (Lates calcarifer) ve hani balıklarının (Epinephelus spp.) yetiştiriciliği için oksijen bütçesi baz alınarak geliştirilmiştir. Model için gereken bilgiler; işletmeye gelen girdi ve çıktı suyunda oksijen konsantrasyonu, su kolonundaki oksijen tüketimi, sedimentteki oksijen tüketimi, yetiştirilen balık tarafından tüketilen oksijen konsantrasyonu, akış hızı, işletme alanı ve kafes derinliğidir (Halide vd., 2009, Şekil 5). 


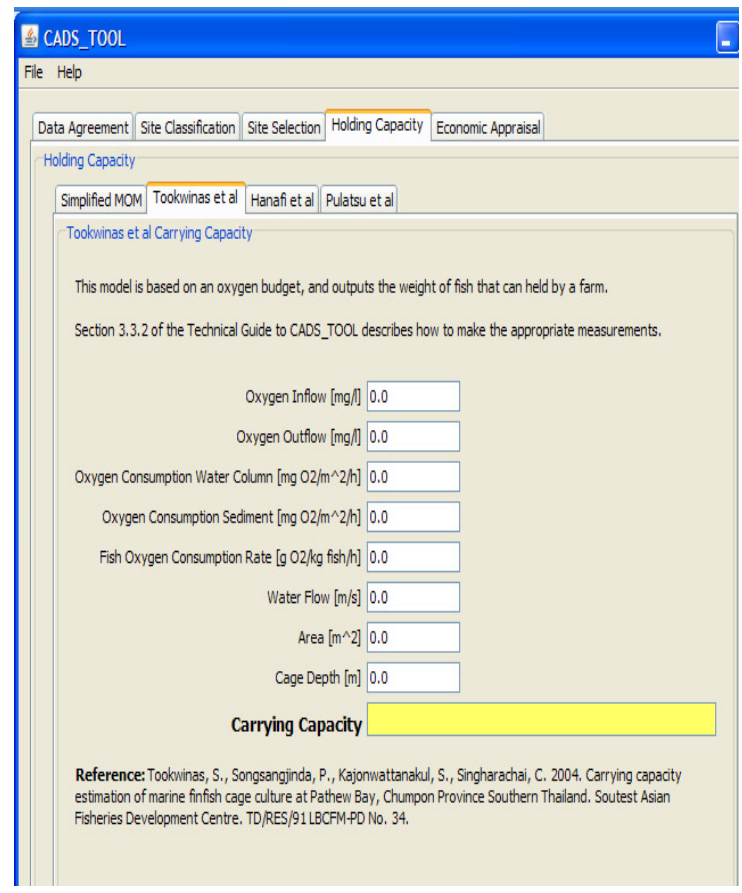

Şekil 5. Taşıma kapasitesinin tahminine ilişkin Tookwinas vd. modeli (Halide vd., 2009).

\subsubsection{Hanafi vd. modeli}

Hanafi vd. tarafindan geliştirilen bu modelde ise, Endonezya'da hani balıklarının (Epinephelus spp.) yarı kapalı denizlerde ve koylarda yetiştiriciliği için oksijen bütçe modeli baz alınmıştır. Model için gereken girdi bilgileri, su kolonundaki oksijen konsantrasyonu, yetiştirilen balığa özgü oksijen sınır değeri, su kolonundaki oksijen tüketimi, denizin kabarması (med hareketi) zamanında koy veya körfezin hacmi ve suyun seyrelme hızıdır (Halide vd., 2009, Şekil 6).

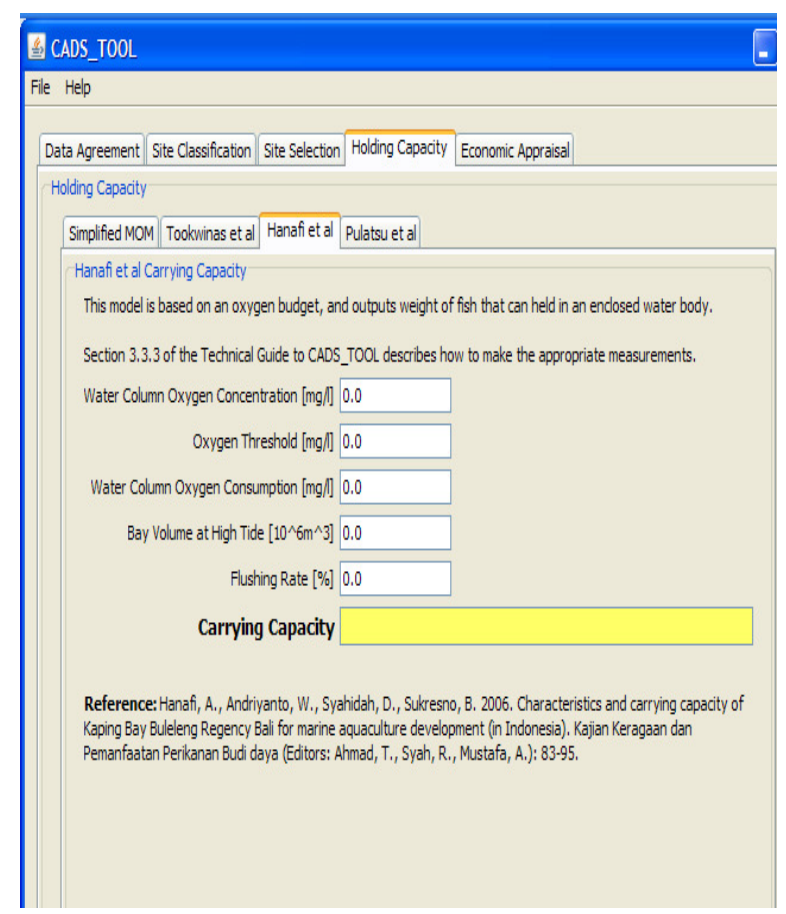

Şekil 6. Taşıma kapasitesinin tahminine ilişkin Hanafi vd. modeli (Halide vd., 2009). 


\subsubsection{Fosfor bütçe modeli}

Fosfor bütçe modeli, Dillon ve Rigler (1974) tarafından geliştirilmiş olup, model için gerekli olan bilgiler; işletme kurulmadan önce göle ilişkin toplam fosfor konsantrasyonu, yetiştiricilik yapılan ortama ilişkin kabul edilebilir toplam fosfor konsantrasyonu, yemin fosfor içeriği, balık tarafindan tutulan fosfor miktarı, yem değerlendirme oranı, gölün ortalama derinliği, göl alanı, göle gelen su toplam su miktarı ve göl hacmidir (Şekil 7).

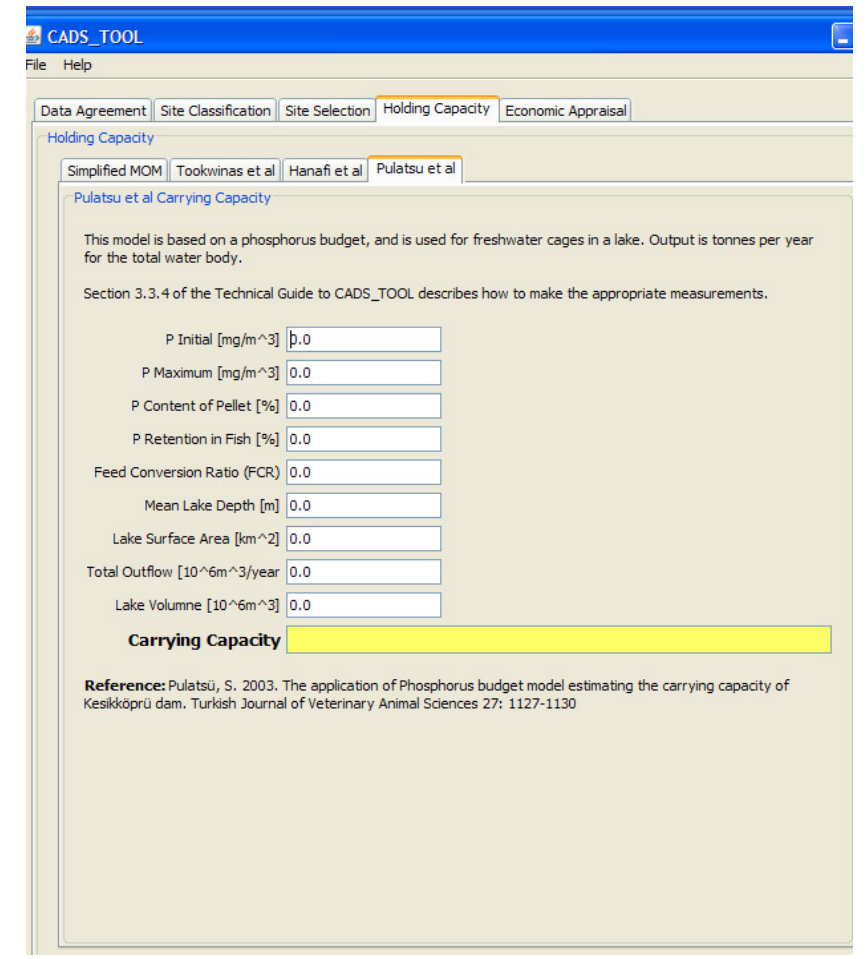

Şekil 7. Taşıma kapasitesinin tahminine ilişkin fosfor bütçe modeli (Halide vd., 2009).

\subsection{Ekonomik değerlendirme}

Ekonomik değerlendirme modülü CADS_TOOL programının son modülüdür. İşletmenin karlılı̆̆ına ilişkin tahminde; taşıma yoğunluğu, kafes hacmi, hasat edilen ortalama balık ağırlığı, yaşama oranı, yem değerlendirme oranı, yem gideri, kafes gideri, yavru gideri, faiz oranı, balık satış fiyatı, birim ürün maliyeti ve yatırılan sermayenin geri dönüş oranı gibi veriler kullanılmaktadır (Şekil 8). 


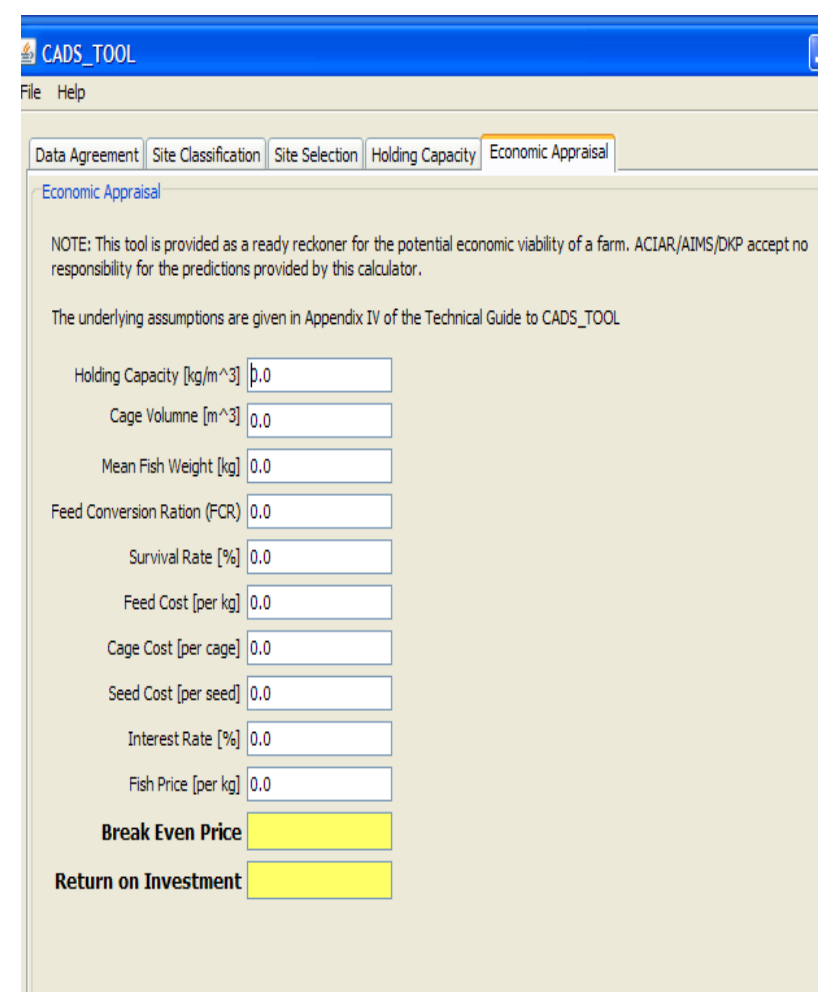

Şekil 8. Ekonomik değerlendirme modülü (Halide vd., 2009).

\section{Sonuç}

Birçok ülkede denizel ekosistemlerde faaliyet gösteren ağ kafes işletmelerinin çevreye olan etkilerinin anlaşılması için izleme programları kullanılmaktadır. Simulasyon modelleri de balık işletmelerinden kaynaklanan organik atıkların, atık sularla bölgesel sulara karışması sonucu oluşacak etkilerin tahmini için geliştirilmiştir. Ancak herhangi bir alıcı ortamın aşırı kullanımını önlemek ve kıyısal kaynakların kullanımını optimize etmek için modelleme ve izleme programları ile çevresel kalite standartlarının bir arada bulunduğu sistemlere ihtiyaç bulunmaktadır. Bu çalışmada MOM (Modelling-Ongrowing Fish Farms-Monitoring) sistemi ile alıcı ortamlarda ağ kafeslerde sürdürülebilir yetiştiricilik için geliştirilen -A ğ Kafeslerde Yetiştiriciliğe İliş̧kin Karar Destek SistemiCADS_TOOL bilgisayar yazılımı; çevre ile dost yetiştiricilik yapabilmek için kısa zamanda güvenilir sonuç verebilecek güncel bir teknolojik yaklaşım olarak sunulmuştur. CADS_TOOL yazılımının pratikte kullanılması, ülkemizde farklı alıcı ortamlarda yoğun dağılım gösteren ağ kafes işletmelerinin yönetiminde ve çevresel durumun izlenmesi konusunda yürütülen çalışmalara katkı sağlayacaktır. 


\section{Beril Özdal ve Serap Pulatsü}

\section{Kaynaklar}

Ackefors, H. and Enell, M. 1990. Discharge of Nutriens from Swedish Fish Farming to Adjacent Sea Areas. Ambio, 19: 2935 .

Alpaslan, A. and Pulatsü, S. 2008. The Effect of Rainbow Trout (Oncorhynchus mykiss Walbaum, 1792) Cage Culture on Sediment Quality in Kesikköprü Reservoir, Turkey. Turkish Journal of Fisheries and Aquatic Sciences, 8 (1): 6570.

Demir, N., Kırkağaç, M., Pulatsü, S. and Bekcan, S. 2001. Influence of Trout Cage Culture on Water Quality, Plankton and

Benthos in an Anatolian Dam Lake. The Israeli Journal of Aquaculture-Bamidgeh, 53 (3-4): 115-127.

Dillon, P.J.and Rigler, F.H. 1974. A Test of a Simple Nutrient Budget Model Predicting the Phosphorus Concentration in

Lake Water. J. Fish.Res.Board Can., 31: 1771-1778.

Ervik A., Hansen, P.K., Aure, J., Stigebrandt, A., Johannessen, P. and Jahnsen, T.1997. Regulating the Local Environment Impact of Intensive Marine Fish Farming I. The Concept of the MOM System (Modelling-Ongrowing fish farmsMonitoring). Aquaculture, 158, 85-94.

Halide, H., Stigebrandt, A., Rehbein, M. and McKinnon, A.D. 2009. Developing a Decision Support System for Sustainable

Cage Aquaculture. Environmental Modelling\&Software, 24, 694-702.

Hansen, P.K., Ervik, A., Schaanning, M., Johannessen, P., Aure, J., Jahnsen, T. and Stigebrandt A. 2001. Regulating the Local Environment Impact of Intensive Marine Fish Farming II. The Monitoring Programme of the MOM System (Modelling-Ongrowing fish farms- Monitoring). Aquaculture, 194, 75-92.

Pulatsü, S. 2003. The Application of Phosphorus Budget Model Estimating the Carrying Capacity of Kesikköprü Dam Lake. Turkish Journal of Veterinary and Animal Sciences, 27(5): 1127-1130.

Stigebrandt, A., Aure, J., Ervik, A. and Hansen, P.K. 2004. Regulating the Local Environment Impact of Intensive Marine Fish Farming III. A Model for Estimation of the Holding Capacity in the Modelling-Ongrowing Fish FarmsMonitoring System. Aquaculture, 234, 239-261.

Yavuzcan, H., Pulatsü, S., Demir, N., Kırkağaç, M., Bekcan, S., Topçu, A., Doğankaya, L., ve Başçınar, N. 2010. Türkiye'de Sürdürülebilir Su Ürünleri Yetiştiriciliği. TMMOB Ziraat Mühendisliği VII. Teknik Kongresi Bildiriler Kitabı: 767789, 11-15 Ocak 2010, Ankara. 